\title{
Drones: 4DT Applications in US Industry and Public Policy
}

\author{
Donna M. Schaeffer \\ Marymount University \\ Patrick C. Olson \\ National University
}

As technologies emerge, public policy can be a means of ensuring that technology makes sense for a culture. For example, as communication technologies emerged in the 19th and 20th centuries, public policy ensured the technology operated in everyone's interests. Public policy is also the means by which the Internet and the field of nanotechnology were able to develop. Most often public policy is used to make sure that completing interests are fairly served, as evidenced by Intellectual Property laws. Drones can be used to perform tasks that are dirty, dangerous, require dexterity, are dear (or expensive) and tedious for humans to do. Some examples are drones in the military and firefighting efforts. Despite the benefits of drones, their application is limited due to the legal constraints and a lack of regulations. Public policy regarding drones is trending towards restrictions. This trend poses an interesting question: Will regulatory restrictions will reduce the utility of drones?

\section{INTRODUCTION}

As technologies emerge, public policy can be a means of ensuring that technology makes sense for a culture. For example, as communication technologies emerged in the $19^{\text {th }}$ and $20^{\text {th }}$ centuries, public policy ensured the technology operated in everyone's interests. Public policy is also the means by which the Internet and the field of nanotechnology were able to develop. Most often public policy is used to make sure that completing interests are fairly served, as evidenced by Intellectual Property laws.

Unmanned Aerial Vehicles (UAVs), commonly called drones, are an emerging technology that is getting a lot of media attention in recent times. A drone is an aircraft without a human pilot on board. Drones are operated by remote control by a pilot or are autonomous, controlled by onboard computers.

Goldman Sachs Research (2018) estimates that drones will be a $\$ 100$ billion marketplace by the year 2020. While the military comprises the majority of the market - $\$ 70$ billion in 2020 , hobbyist and consumer use is growing, and estimated to reach $\$ 17$ billion. Business and non-military government use is expected to reach $\$ 13$ billion in 2020. Industries that will be enhanced with drone use include construction and agriculture. Drone could also play a role in insurance claims, off-shore oil and gas refining, journalism and cinematography. Other applications include those used by police, fire, coast guard, and border patrol.

A drone may be considered a robot, given that the definition of robot is a machine capable of carrying out a complex series of actions automatically, especially one programmable by a computer (OED, 2018). 
For decades, authors have categorized the tasks to which robots are well-suited into "D's": tasks that are dull, dirty, and dangerous. A fourth " $D$ " - dear - was added by McAfee and Brynjolfsson (2017). Bernier (2013) indicates a fifth " $\mathrm{D}$ " - dexterous is an appropriate quality of robots.

Rather than use the word "dull", we substitute the word tedious, yielding the term 4DT. Many jobs for which drones are suitable combine one or more of the 4DT characteristics; for example, monitoring of pipelines is tedious, can be dangerous if leaks are discovered, and may require dexterity if the pipeline goes through inaccessible terrain. The United States Bureau of Labor Statistics (2016) reports a median salary of $\$ 76,208$. For all wage-earners, the median salary was $\$ 31,099$ in 2017 . Thus, since pipeline inspection is quite labor intensive, it is fair to say that the costs of pipeline inspection is "dear."

Jobs that are "dirty," that is contaminated or toxic, are good applications for drones. For example, nuclear waste site cleanup exposes human workers to radiation. Drones can map nuclear waste sites. The US Military provided drones to fly over and into the damaged nuclear reactors a Japan's Fukushima site (Brady, 2017). Researchers at the Autonomous Robots Lab in the University of Nevada College of Engineering have developed a prototype robot drone with inertial sensors, lidar, cameras, and radiation/chemical sensors for the United States Department of Energy. Drones could even perform cleanup duties, as the "Waste Shark" drone is currently doing at the Port of Rotterdam. In a test program, four drones collect up to 1,100 pounds of waste from the ocean floor and one foot below (Atherton, 2016).

Brady (2017) describes how military drones can do "dirty" jobs, e.g., flying into an atomic mushroom cloud like the Grumman F6F Hellcat did in 1946 when it flew into Bikini Atoll where the atomic bomb was tested to take photos of the inside of the cloud. Military drones also do tedious jobs like a 24-hour or 48-hour flight that is beyond human endurance and dangerous missions.

Drones under development are demonstrating dextrousity. Researchers at Stanford University unveiled the Stanford Climbing and Aerial Maneuvering Platform (SCAMP), a prototype robot/drone that can fly, land, perch on surfaces and climb up walls (Pope, 2016). Drones can make deliveries or gather information by going where there are no roads, or where road access may be limited at certain times of the year. Raptopoulos (2013) reports on using drones to deliver medical supplies to camps in Haiti after the 2010 earthquake, when roads were impassable.

There are many examples of drones performing dangerous work. The field of firefighting provides several excellent examples. Dunn (2018) describes how drones are being used at wildfires to give fire commanders an overall view of a fire, identifying small but growing brush fires, flame spread directions, and hot spots. The characteristic of dexterity is exhibited as drones drop water in areas that may be otherwise inaccessible. It is common knowledge that being on the roof of a burning building is quite dangerous - in the first half of 2018, newspapers reported deaths of firefighters in Lawrenceburg, TN (Tamburin and Alund, 2018), York, PA (Kessler et al, 2018), Philadelphia, PA (Shaw and Gambacorta, 2018). Dunn (2018) describes that a drone was used by the New York Fire Department identified that the fire had already spread to the common roof space, and showed the rear of the building, as well as the air and light shafts. The drone provided information that was used to assess the structure's stability and areas to avoid. Drones provide an advantage in urban areas where access to the rear of buildings may be limited. Table 1 presents a taxonomy of drones as applied to 4DT. 
TABLE 1

TAXONOMY OF DRONES AND 4DT

\begin{tabular}{|c|c|c|c|c|}
\hline Type & Description & Usage & Example & $\begin{array}{c}\text { 4DT } \\
\text { Characteristic }\end{array}$ \\
\hline Target and Decoy & $\begin{array}{c}\text { provides ground and } \\
\text { aerial gunnery a } \\
\text { target that simulates } \\
\text { an enemy aircraft or } \\
\text { missile }\end{array}$ & Military & $\begin{array}{c}\text { Integrated } \\
\text { Dynamics } \\
\text { Tornado }\end{array}$ & Dangerous \\
\hline Reconnaissance & $\begin{array}{c}\text { provides battlefield } \\
\text { intelligence }\end{array}$ & Military & Lockheed D-21 & Dangerous \\
\hline Combat & $\begin{array}{c}\text { provides attack } \\
\text { capability for high- } \\
\text { risk missions }\end{array}$ & Military & $\begin{array}{c}\text { Northrup } \\
\text { Grumman X- } \\
47 \mathrm{~B}\end{array}$ & $\begin{array}{c}\text { Dangerous } \\
\text { Logistics }\end{array}$ \\
\hline Civil and commercial \\
UAVs & $\begin{array}{c}\text { Used in agriculture, } \\
\text { aerial photography } \\
\text { any type of data } \\
\text { collection, and by } \\
\text { hobbyists }\end{array}$ & $\begin{array}{c}\text { Military and } \\
\text { Commercial }\end{array}$ & Flytrex Sky & $\begin{array}{c}\text { Dextrous } \\
\text { Dear }\end{array}$ \\
\hline Dangerous \\
\hline
\end{tabular}

\section{POLICY AND REGULATION}

When humans perform the jobs described in the previous section, the jobs are regulated by the United States Occupational Safety and Health Administration (OSHA) of the United States Department of Labor. It was initiated by the Occupational Safety and Health Act of 1970, and its mission is to assure safe and healthful working conditions for working men and women by setting and enforcing standards and by providing training, outreach, education and assistance. OSHA's global counterparts include bodies such as the European Union's Agency for Safety and Health at Work (EU-OSHA) and the International Labour Organization (ILO). OSHA and related global agencies do not have regulations about drones, although EU-OSHA and ILO have made statements about drones either replacing human workers or facilitating their own inspections. EU-OSHA encourages the use of drones to reduce workers' exposure to hazardous environments and to improve monitoring (EU-OSHA, 2017). A 2015 International Labour Organization Report describes drones used in United Arab Emerites for routine construction inspection and recognizes drones would be a useful technology to employ for its own labour inspections (Galazka, 2015).

The use of drones is regulated; the applications that drones for which are used are not yet subject to regulation in the United States. The Federal Aviation Administration (FAA) and the Transportation Security Administration have jurisdiction over drones. It is helpful to view regulation in a series of steps from acquiring drones to their use.

When an individual acquires a drone, they must register the drone with the FAA. There are two types of registration, for drones used by hobbyists and for recreational purposes and for drones that serve a commercial use. The FAA issues a Remote Pilot Certificate that pilots of commercially-used drones are required to hold.

Certain regulations apply to all drones, regardless of their use. For examples, drones are prohibited within a 15-mile radius of Ronald Reagan National Airport, which renders the nation's capital 
metropolitan area a "No Drone Zone." Drones may be operated with restrictions in the geographical area between 15 to 30 miles from Washington, D.C. The total weight of the UAS must be less than 55 pounds and flights are restricted to an altitude of 400 feet and must be within the operator's visual line-of-sight. The FAA restricts the use of drones in the airspace at several airports across the country, the Grand Canyon National Park, and Niagra Falls.

The FAA may restrict drones temporarily in certain areas, due to hazardous conditions, such as a wildfire or chemical spill, for security reasons, e.g. a gathering of world leaders at the United Nations. Temporary flight restrictions may also be issued in and around stadiums during Major League Baseball, National Football League, NCAA Division One Football, NASCAR Sprint Cup, Indy Car, and Champ Series races.

The Law of Armed Conflict applies to drones that are used by the military during armed conflicts (Dyndel, et al 2017). In a war situation, drones are considered the same as any weapon, weapon system, or weapon platform. Thus, they must be directed solely at lawful targets and must not cause excessive collateral damage

\section{LIMITATIONS TO DRONE USE}

Gomez and Greene (2017) hold that despite the benefits of drones, their application is limited due to the legal constraints and a lack of regulations. Public policy regarding drones is trending towards restrictions. This trend poses an interesting question: Will regulatory restrictions will reduce the utility of UAVs?

In addition to US law, states and municipalities have enacted local ordinances that restrict the use of drones in particular areas. Dunn (2018) points out that 75\% of New York City air space is restricted. Any use of drones required approval from the Federal Aviation Agency, and is limited to a height of 200 feet.

\section{CONCLUSION}

The idea that each emerging technology is unique seems obvious. However, it is less obvious that the use of public policy for each emerging technology is unique. Yet, that must follow from the idea that each emerging technology is unique, especially if the goal of public policy applied to technology is to ensure that the technology is established and diffused in for the common good in the culture. The case of drones and public policy fits the concepts described above. The unique aspect of public policy for drones is that regulation of the use of drones will impact the use of drones in our culture. In some sense, it is always hoped that public policy will help diffuse the use of a new technology for the common good. However, in the case of drones, public policy may have a negative impact. In effect, drones have the capacity to take the place of hazardous human activity, thus the limitation of their use by public policy could retard or even stop the diffusion of the use of drones for the elimination of hazardous work.

\section{REFERENCES}

Atherton, K. D. (2016, September 12). Meet 'Waste Shark', The Drone That's Picking Up Garbage From The Oceans" Popular Science. Retrieved from https://www.popsci.com/waste-shark-is-garbagecollecting-sea-drone

Bernier, C. (2013, August 19). Dexterous Manipulation: Robot Arms - Sensing and Controls. Retrieved from https://blog.robotiq.com/bid/66566/Dexterous-Manipulation-Robot-Arms-Sensing-andControls

Brady, H. (2017, November 28). Drones Doing Dirty and Dangerous Jobs. Retrieved from https://airandspace.si.edu/stories/editorial/drones-doing-dirty-and-dangerous-jobs

Dunn, V. (2018). Private Correspondence. 
Dyndel, G., Berntsen, T. A., \& Redse-Johansen, S. (2017, 28 July). Autonomous Military Drones: No Longer Science Fiction. NATO Review, Retrieved from https://www.nato.int/docu/review/2017/also-in-2017/autonomous-military-drones-no-longerscience-fiction/EN/index.htm

EU-OSHA (2017). Foresight on New and Emerging OSH Risks Associated With Information and Communications Technologies by 2025. Retrieved from https://osha.europa.eu/sites/default/files/seminars/.../Seminar\%20summary_8.pdf

Galazka, A. M. (2015). Report on the global survey into the use of information and communication technologies in national labour administration systems. International Labour Office.

Goldman Sachs Research (2018). Drones: Reporting for Work. Retrieved from http://www.goldmansachs.com/our-thinking/technology-driving-innovation/drones/

Gómez, C., \& Green, D. R. (2017). Small unmanned airborne systems to support oil and gas pipeline monitoring and mapping. Arabian Journal of Geosciences, 10(9), 202.

Kessler, B., Boeckel, T., \& Czech, T. (2018, March 22). Two firefighters killed in York fire identified; two others injured after collapse. York Daily Record. Retrieved from https://www.ydr.com/story/news/2018/03/22/rescue-crews-called-scene-york-fire-after-severalpeople-trapped-911-reports/450472002/

Marr, B. (2017, 16 October). The 4 Ds Of Robotization: Dull, Dirty, Dangerous And Dear." Forbes. Retrieved from https:/www.forbes.com/sites/bernardmarr/2017/10/16/the-4-ds-of-robotizationdull-dirty-dangerous-and-dear/

McAfee, A., \& Brynjolfsson, E. (2017). Machine, Platform, Crowd: Harnessing Our Digital Future. W. W. Norton \& Company.

Oxford English Dictionary. (2018). Robot. Retrieved from https://en.oxforddictionaries.com/definition/robot

Pope, M. (2016, 16 March). Stanford's Flying, Perching SCAMP Robot Can Climb Straight Up Walls. IEEE Spectrum. Retrieved from https://spectrum.ieee.org/automaton/robotics/drones/stanfordsflying-perching-scamp-can-climb-up-walls

Raptopoulos, A. (2013). No roads? There's a drone for that. Retrieved from https://www.ted.com/talks/andreas_raptopoulos_no_roads_there_s_a_drone_for_that/transcript

Shaw, J., \& Gambacorta, D. (2018, January 6). Firefighter, resident killed $\overline{\text { in }} \overline{\text { North }} \overline{\text { Philly rowhouse }}$ blaze, collapse. The Inquirer. Retrieved from http://www.philly.com/philly/news/north-phillyfire-colorado-street-injuries-20180106.html

Tamburin, A., \& Alund, N. N. (2018, February 13). Fire chief on death of Lawrenceburg firefighter Jason Dickey: I've lost one of my boys. The Tennessean. Retrieved from https://www.tennessean.com/story/news/crime/2018/02/13/1-firefighter-killed-2-injuredlawrenceburg-house-fire/332337002/ 